Veritas Et Scientia

Vol. $8, \mathrm{~N}^{\circ} 2$.

Julio - diciembre del 2019.

ISSN Edición Online: 2617-0639

https://doi.org/10.47796/ves.v8i2.141

\title{
MARCO NORMATIVO Y SANCIÓN PECUNIARIA EN LA INCAUTACIÓN DE DINERO POR TRANSPORTE TRANSFRONTERIZO EN UN CENTRO DE ATENCIÓN EN ZONA DE FRONTERA.
}

\author{
REGULATORY FRAMEWORK AND PECUNIARY SANCTION IN THE INCAUTATION OF CROSS-BORDER \\ MONEY IN A BORDER CARE CENTER.
}

Vanessa del Pilar Muñoz Barrenechea ${ }^{1}$
Elena Miriam Chávez Garcés ${ }^{2}$

Aceptado: $17 / 09 / 2019$

Publicado online:15/01/2020

\begin{abstract}
RESUMEN
La investigación tiene como propósito demostrar la influencia del marco normativo en la omisión a la sanción pecuniaria en la incautación de dinero por transporte transfronterizo. Para ello se trabajó una investigación básica, de nivel explicativo, habiendo seleccionado como muestra 163 casos de intervenciones en el centro de atención fronteriza Santa Rosa y aplicaron fichas de análisis documental para recoger la información. Los resultados cualitativos sobre el marco normativo demuestran que la ley 28306 ha sufrido modificatorias y variaciones sustanciales entre el año 2004 y 2016; el D.L. 1249 que regula el traslado de dinero transfronterizo, no contempla los casos en los cuales corresponde la incautación de dinero, medida cautelar dispuesta por el fiscal, No existe un criterio objetivo para optar entre la figura de retención (aduana) o incautación (fiscalía). El caso 265-2017, se evidencia que existe una infracción en la vía administrativa, pero al disponer el archivo del caso, por la fiscalía, se dispone la devolución del dinero, sin tener en cuenta el cumplimiento del pago de la multa; el $77.27 \%$ de las intervenciones existen vacíos legales que generan conflictos normativos en su aplicación práctica, entre los operadores de aduanas, policía Nacional y Ministerio público. Entre el 2016 y 2018 se multó por la suma de $S / 3,652,784.00$, sin embargo, la deuda por cancelar es de $S / 1,679,281.00$, que representa el $45.97 \%$ de omisión al cumplimiento de la sanción pecuniaria. Se concluye que los vacíos y deficiencias técnicas del marco normativo que regula la obligación de declarar
\end{abstract}

\footnotetext{
${ }^{1}$ Maestro en Management Internacional. Especialista intendencia de aduana de Tacna, Tacna, Perú

${ }^{2}$ Analista de Implantación del Ministerio de Economía y Finanzas (MEF). Académico de la ESPG de la UNJBG,Tacna, Perú
} 
el ingreso y salida de dinero del país, viene influenciando en la omisión al cumplimiento de la sanción pecuniaria por traslado de dinero sin declarar o declarado falsamente.

Palabras claves: Marco normativo, omisión a la sanción pecuniaria, dinero transfronterizo

\begin{abstract}
The purpose of the investigation is to demonstrate the influence of the regulatory framework on the omission of pecuniary sanctions in the seizure of money by cross-border transport. To this end, a basic, mixed investigation was carried out, at the explanatory level, having selected as sample 163 cases of interventions in the Santa Rosa border attention center and documentary analysis cards were applied to collect the information. The qualitative results on the regulatory framework show that Law 28306 has undergone modifications and substantial variations between 2004 and 2016; the D.L. 1249 that regulates the transfer of cross-border money, does not contemplate the cases in which the seizure of money corresponds, precautionary measure ordered by the prosecutor. There is no objective criterion to choose between the figure of retention (customs) or seizure (prosecutor's office). Case 265-2017, it is evident that there is an infraction in the administrative way, but when arranging the file of the case, by the prosecution, the return of the money is arranged, without taking into account the payment of the fine; In $77.27 \%$ of the interventions there are legal gaps that generate normative conflicts in their practical application, among customs operators, National Police and Public Ministry. Between 2016 and 2018 , the sum of $S / 3,652,784.00$ was paid, however, the debt to be paid is $S$ / $1,679,281.00$, which represents $45.97 \%$ of the failure to comply with the pecuniary penalty. It is concluded that the gaps and technical deficiencies of the regulatory framework that regulates the obligation to declare the entry and exit of money from the country, is influencing the failure to comply with the pecuniary sanction for transferring money without declaring or falsely declared.
\end{abstract}

Key words: Normative framework, omission of pecuniary sanction, crossborder money.

\title{
INTRODUCCIÓN
}

El Centro de Atención en Frontera Santa Rosa (CAFSR), circunscripción de la Aduana de Tacna, es el segundo lugar después de la Aduana Aérea del Callao, que maneja mayor flujo de dinero, por ella ingresan y salen del país personas trasladando una gran cantidad de dinero, en efectivo o en instrumentos negociables, quienes para evitar el control por parte de la Autoridad Aduanera crean modalidades de evasión ocultamiento o repartición, que dificultan el efectivo control del origen del dinero. El propósito de la investigación es relacionar el marco normativo con la omisión de las sanciones que derivan del traslado ilícito de dinero en la frontera de Perú y Chile. Entre las diferentes infracciones que vulneran el control aduanero, se encuentra el transporte de dinero 
transfronterizo, no declarado o declarado falsamente, considerado como una modalidad vinculada al delito de lavado de activos, el cual, conforme a los reportes del CAFSR viene en aumento, llamando la atención del Estado, por lo que a través de sus Instituciones ha sumado esfuerzos en la lucha frontal contra el lavado de activos, convertido hoy en día en un factor que desestabiliza el orden económico y perjudica de manera grave el tráfico comercial. En esta línea, se ha regulado, en base a estándares internacionales dispositivos legales, como la Ley $N^{\circ} 27693$ (2002), Ley que que crea la Unidad de Inteligencia Financiera hasta el Decreto Legislativo $N^{\circ} 1249$ (2016), Decreto Legislativo que dicta medidas para fortalecer la prevención, detección y sanción del Lavado de Activos.

Huber Huayllani Vargas (2016) concluye que el lavado de activos es uno de los fenómenos criminales que más atención a recibió a nivel internacional razón por el cual son numerosos los instrumentos internacionales, multi y bilaterales, que tratan de enfrentarse a él y que ha motivado que diferentes países no solo se enfrenten a través de medidas punitivas sino también con medidas preventiva y fiscalizadoras focalizado en el sistema financiero. Guillén Enriquez, Carlos Noé (2016) evidencia que en los últimos ocho años el lavado de activos se ha incrementado en nuestro país a 12,840 millones de dólares, teniendo como fuente de las ganancias ilícitas al tráfico ilícito de drogas. Guillén Enriquez concluye que no existe unidad de criterio en los operadores de justicia para la aplicación de la validez de la prueba indiciaria en la investigación y judicialización del delito de lavado de activos proveniente del TID. Díaz Beltrán T. (2017) refiere que existe un incorrecto tratamiento de la acreditación de la comisión de lavado de activos, por el inadecuado ejercicio interpretativo de la normativa actual. Lentz tuvo como referente práctico los casos resueltos por el Tribunal Fiscal en el periodo comprendido desde el año 2009 al 2016. Concluye que, para solucionar la falta de claridad en los supuestos de infracción, se requiere adecuar los alcances al principio de tipicidad. Gamarra Podbrscek G. (2017) observó que la autoridad aduanera peruana deberá observar un proceso sancionador respetuoso del principio de proporcionalidad. Este principio es aplicable no solo en las actuaciones que realice la autoridad aduanera ante las operaciones de comercio exterior de los Países Miembros de la Comunidad Andina, sino también ante todo Miembro de la Organización Mundial del Comercio (OMC).

\section{OBJETIVOS}

a. Identificar las lagunas jurídicas en el marco normativo relacionado a la infracción administrativa en el transporte de dinero transfronterizo.

b. Evaluar la aplicación de las sanciones pecuniarias en la incautación de dinero por transporte transfronterizo en el Centro de Atención Fronteriza Santa Rosa.

\section{METODOLOGÍA}

Investigación de tipo básica, cualitativa - cuantitativa y se limita a los aspectos normativos y operacionales que enmarcan las intervenciones de dinero en la Administración Aduanera, en el Centro de Atención en Frontera Santa Rosa, entre los 
años 2015 al 2018. La población está constituida por un promedio de 163 casos de Intervenciones de dinero transfronterizo, en posesión de viajeros quienes posterior a su control migratorio omitieron efectuar su declaración jurada de dinero. Se procedió a recopilar datos mediante solicitudes de acceso a la Información ante la Intendencia de Aduana de Tacna. Asimismo se solicitó consulta de expedientes archivados respecto de casos de infracción administrativa por traslado de dinero transfronterizo en el Centro de Atención en Frontera Santa Rosa y casos fiscales iniciados por presunto lavado de activos.

\section{RESULTADOS}

La normativa nacional para la sanción del lavado de activos tiene su origen en tratados internacionales, en la Convención de las Naciones Unidas contra el Tráfico llícito de Estupefacientes y Sustancias sicotrópicas - Convención de Viena de 1988 y por la Convención de las Naciones Unidas contra la Delincuencia Organizada Transnacional Convención de Palermo de 2000 y las 40 recomendaciones de la GAFI (Grupo de Acción Financiera Internacional). Los Estados a partir de la Convención de Viena de 1988, deciden impulsar sistemas normativos, destinados a cubrir la regulación de todos los aspectos concernientes a la operatividad del lavado de activos, es así que se configuran dos modelos de regulación. Una de naturaleza administrativa orientado a prevenir conductas ilícitas y otros de naturaleza penal, dirigida a establecer la tipificación y sanción punitiva ante conductas ilícitas. Ore Sosa (2018) refiere que la configuración actual del delito de lavado de activos obedece a instancias supranacionales, impulsada por organizaciones internacionales con el nuevo pretexto de la lucha contra la criminalidad organizada. El delito de lavado de activos ha sido objeto de múltiples modificaciones; estas han supuesto no sólo el incremento de las penas conminadas, sino también la indebida ampliación de los tipos penales en la lucha contra el crimen organizado. Concuerdo con Ore Sosa E. (2018) al señalar que la constante modificación normativa no coadyuva a la consolidación de criterios doctrinales o jurisprudenciales, en corto plazo pueden quedar obsoletos o con una nueva configuración típica que acarrea problemas de inseguridad jurídica, lesionando el principio de legalidad y la correcta aplicación de la Ley Penal en el tiempo.

El Decreto Legislativo $N^{\circ} 1106$, establecía en su numeral 6.3, literal a) las consecuencias que se presentan ante el incumplimiento de sus párrafos precedentes, incorpora la figura de la retención, la cual consistía en la desposesión temporal del monto total de dinero en efectivo o de los instrumentos financieros negociables emitidos "al portador" además la aplicación de una sanción pecuniaria equivalente al treinta por ciento $(30 \%)$ del valor no declarado, consecuencia de la omisión o falsedad del importe declarado bajo juramento por parte de su portador. Además, se aplicaba la retención temporal del monto de dinero en efectivo o de los instrumentos financieros negociables emitidos "al portador" que exceda los US $\$ 30,000.00$ (treinta mil y 00/100 dólares de los Estados Unidos de América).

Con la dación del Decreto Legislativo N 1249 mejora el texto legal del DI. 1106, precisa y aclara que procederá la retención temporal del monto íntegro de dinero en efectivo 0 
de los instrumentos financieros negociables al portador en caso se haya omitido declarar o se haya declarado falsamente y a la aplicación de una sanción equivalente al pago del treinta por ciento (30\%) del valor no declarado. Al igual que la 1106 , prescribe que procede la retención temporal del monto de dinero en efectivo o de los instrumentos financieros negociables emitidos "al portador" que exceda los US $\$ 30,000.00$ (treinta mil y 00/100 dólares de los Estados Unidos de América) o su equivalente en moneda nacional u otra extranjera, sin embargo precisa que procede en caso se haya efectuado la declaración total del dinero en efectivo y/o de los instrumentos financieros negociables emitidos "al portador", pero su valor supere el monto indicado. Se contempla además que la SUNAT es la entidad encargada de supervisar y aplicar las sanciones ante el incumplimiento del deber de declaración y el monto de esta, prevé una sanción de multa y la retención temporal del monto.

La normativa actual agrega un literal al punto 6.3, en la cual narra el procedimiento a seguir por parte del personal SUNAT. Que, en el marco de la intervención, el personal de la SUNAT procede a elaborar un acta de retención suscrita por el personal SUNAT, la persona intervenida y el representante del Ministerio Público, quien procede de acuerdo a sus atribuciones. Finalmente se dispone que en caso el Ministerio Público, en uso de sus atribuciones, disponga la incautación, no procede la retención temporal por parte de la SUNAT, la que debe informar a la Unidad de Inteligencia del Perú (UIF-Perú).

Anteriormente, con el DL. 1106, se estableció que el dinero y los instrumentos financieros negociables serán depositados en una cuenta del Banco de la Nación donde se mantendrá en custodia, con lo cual se precisaba la autoridad nacional encargada de aplicar la normativa administrativa y el sistema de sanciones, acatando lo señalado en las Recomendaciones del GAFI, precisándose que la autoridad aduanera informará inmediatamente a la UIF - Perú sobre la retención efectuada. Con la modificatoria normativa, lo anterior ha variado a razón que, en la operatividad al presentarse una intervención de dinero en el Centro de Atención en Frontera, la potestad para decidir las diligencias y atribuciones a realizar la tiene el fiscal, el Ministerio Público dado que la norma establece que en caso el MP en uso de sus atribuciones disponga la incautación no procede la retención temporal por parte de la SUNAT. Si bien el texto legal contempla que la autoridad aduanera deberá proceder con la retención ello no es así, debido a que en algunos casos estaremos ante una infracción administrativa que dará lugar a una retención y a la elaboración del Acta de Retención y en otros casos ante la presunta comisión del delito de Lavado de Activos, en cuyo caso el dinero se incauta por disposición fiscal.

Que, ante una incautación de dinero dispuesta por el Fiscal, la Aduana - SUNAT no elabora ningún acta administrativa, solo la elaboración del informe respectivo que da cuenta de la intervención. Actualmente el único documento con el que cuenta la aduana para aplicar la sanción respectiva del treinta (30\%) pese a no existir acta alguna con firma del intervenido. La incautación es una medida cautelar o de aseguramiento del decomiso, cuya finalidad es instrumental. Cuando el carácter de urgencia o necesidad lo exijan puede producirse en una investigación preliminar a cargo del Fiscal con cargo a ser ratificada o dejada sin efecto en su oportunidad por el juez de la causa. 
Respecto al destino de los fondos retenidos e incautados, el DL. 1249 establece que el dinero en efectivo $y / o$ instrumentos financieros negociables emitidos "al portador" retenidos se mantienen en custodia en el Banco de la Nación, por cuenta de la Superintendencia de Banca, Seguros y Administradoras Privadas de Fondos de Pensiones (SBS), hasta el pronunciamiento que realice el Ministerio Público o el Poder Judicial. En cambio, cuando el dinero es incautado por disposición Fiscal es depositado a la cuenta de la CONABI - Comisión Nacional de Bienes. El numeral 6.4 recoge una presunción probatoria al establecer que la no acreditación del origen lícito del dinero o de los instrumentas financieros negociables emitidos "al portador" en el plazo establecido, se considera indicio de la comisión del delito de lavado de activos, sin perjuicio de la presunta comisión de otros delitos. En estos casos, la UIF-Perú informará al Ministerio Público para que proceda conforme a sus atribuciones.

Al respecto Rosas Castañeda Juan Antonio (2015) en su obra La Prueba en el Delito de Lavado de Activos, cita a Prado Saldarriaga quien escribió en su obra Criminalidad organizada y lavado de Activos, que artículo 3 del Decreto Legislativo 1106, modificado con el 1249, encuentra dificultades hermenéuticas y prácticas debido a la coexistencia de disposiciones legales administrativas que regulan el régimen de declaración y modalidad forma de ingreso o egreso personal, por puntos de frontera del territorio nacional, de divisas o instrumentos financieros al portador. Las dificultades consisten en determinar en qué momento se debe producir la intervención del Ministerio Público, esto es si la intervención es en el complejo fronterizo debe realizar lo la autoridad aduanera, o si esta intervención debe ser realizada con juntamente con la Policía y el Ministerio Público. Del texto de la sexta disposición final antes citado, se desprende que ante el supuesto de falsedad en la declaración y posesión de dinero en efectivo por parte de una persona que se encuentra traspasando un control fronterizo o migratorio, en principio se trataría de una intervención administrativa con participación de la autoridad aduanera, quien tiene la potestad además de retener el dinero no declarado o que exceda el tope precisado en la norma. Esta autoridad aduanera remite dicha información a la Unidad de Inteligencia Financiera del Perú y es ante la UIF que el portador tiene 72 horas para acreditar el origen lícito del mismo, sino lo hiciere este hecho será indicio de la comisión del delito de lavado de activos, lo cual debe ser comunicado al Ministerio Público; con lo cual, la intervención del Ministerio Público recién comenzaría desde ese momento (p.204)

Con la modificatoria ello no ha variado radicalmente, ahora se conoce que la oportunidad de intervención del Ministerio Público es desde el inicio, dado que es el quien firma conjuntamente con el personal SUNAT y la persona intervenida el Acta de Retención. Con ello se han mesclado dos intervenciones: administrativas y penales cuyas funciones no se encuentran delimitadas, no existe un parámetro de actuación dado que diversas entidades confluyen en una intervención. Con el DL 1106, la autoridad aduanera era la encargada del procedimiento administrativo en la figura de la retención lo que permitía ser más eficiente en el trabajo, actualmente la SUNAT se encuentra supeditada a la función fiscal, en todos los casos, al no existir una fiscalía especializada en lavado de activos en la Ciudad de Tacna, y al encontrarse el Centro de Atención en 
Frontera a una hora aproximada de la ciudad, genera que los casos de intervención de dinero se dilaten en el tiempo, pues el fiscal al tener a su cargo otros delitos de distinta naturaleza, no le permite tener exclusividad en la materia para la prosecución de los ilícitos que se presentan en la frontera generando riesgos de toda índole.

Sobre estos puntos la norma no es clara y ello se está advirtiendo problemas en la aplicación práctica dado a conocer en el quehacer diario de los oficiales de aduana especializados en Tráfico llícito de Mercancías (TIM), ubicados en el Centro de Atención en Frontera Santa Rosa en cuanto a: a) La norma si contempla los casos en los cuales corresponde la retención de dinero o instrumento financiero negociable al portador $y$ en consecuencia la aplicación de la sanción de multa del $30 \%$ del valor no declarado o declarado falsamente - principio de objetividad b) La norma no contempla los casos en los cuales corresponde la incautación de dinero, medida cautelar dispuesta por el fiscal, se entiende que se opta por la dicha medida cuando hay indicios razonables de vinculación con el delito de lavado de activos. No existe un criterio objetivo para optar entre una figura u otra. c) Oportunidad de intervención del Ministerio Público, momento en el que una intervención de tipo administrativa se transforma en una de tipo penal d) Si no procede la retención temporal del dinero ni a la elaboración del Acta de Retención alguna por parte del personal de Aduanas, debido a que el Fiscal considera que hay indicios razonables que vinculen al intervenido con la comisión del delito de lavado de activos, la norma no contempla acerca de la oportunidad de la aplicación de la sanción de multa por parte de la autoridad aduanera, dado que ella es consecuencia directa de una infracción administrativa, que deviene de una intervención plasmada a través de un acta. e) Que la norma no contempla si procede la multa del 30\% en los casos de incautación de dinero dispuesta por el Ministerio Público. f) La norma desarrolla el tema de la devolución por parte de la SBS del dinero en efectivo y/o instrumentos financieros negociables emitidos "al portador" retenidos, empero no desarrolla la devolución del dinero en los casos de incautación dispuesta por el Ministerio Público y no sabemos si procederá algún descuento en casos de incautación de dinero cuando el intervenido no ha cumplido con el pago de la sanción administrativa.

Por otro lado, pasando a la vía penal El decreto Legislativo 1249, modifica de los artículos 2, 3 y 10 del Decreto Legislativo $\mathrm{N}^{\circ} 1106$, en lo sucesivo nos enfocaremos sobre el artículo 3, que recoge como modalidad típica una tercera forma que se encuadra dentro del tipo penal de lavado de activos, que regulan los actos de transportar o trasladar dentro del territorio nacional dinero en efectivo o instrumentos financieros negociables de origen ilícito y los actos de hacer ingresar o salir del país tales bienes, con el texto siguiente: al que transporta, traslada, ingresa o saca del país dinero o instrumentos financieros negociables emitidos "al portador" de origen ilícito. Esta es una modalidad incorporada por el D.L. 1106, ya que anteriormente sólo se contemplaban dos formas: a) actos de conversión y transferencia y b) actos de ocultamiento y tenencia, ubicados en los artículos 1 y 2 respectivamente.

El artículo 3) ha sido modificado para incorporar como modalidades típicas el transporte o traslado "consigo o por cualquier medio" de "dinero en efectivo o instrumentos 
financieros negociables emitidos al portador", cuyo origen ilícito conoce o debía presumir el autor. Con ello se sustituye la referencia genérica de títulos valores y agrega como modalidad típica el hacer ingresar o salir del país bienes que se lleva consigo o por cualquier otro medio.

Este tipo penal se encontraba recogido en la Ley 27765 Ley Penal contra el Lavado de Activos del 20 de junio de 2002, cuyo artículo 2 establecía "Actos de Ocultamiento y Tenencia El que adquiere, utiliza, guarda, custodia, recibe, oculta, administra o transporta dentro del territorio de la República o introduce o retira del mismo o mantiene en su poder dinero, bienes, efectos o ganancias, cuyo origen ilícito conoce o puede presumir, y dificulta la identificación de su origen, su incautación o decomiso, será reprimido con pena privativa de la libertad no menor de ocho ni mayor de quince años y con ciento veinte a trescientos cincuenta días multa.". concreción que respondía a la Recomendación Especial del GAFI, IX del 22 de octubre de 2004 sobre los corredores - "couriers" de dinero que suponen una antigua modalidad de lavado de activos transnacional y a la actual Recomendación $\mathrm{N}^{\circ} 32$, que aborda el tema del Transporte en Efectivo. Resulta necesario precisar que La Recomendación 32 del GAFI hace hincapié en la creación de un sistema de declaración a cargo de una autoridad nacional determinada que tenga capacidad de inmovilizar el dinero que se pretende transportar, así como de la aplicación de mecanismos de confiscación y decomiso de los mismos. Sobre el tema Rosas Castañeda Juan Antonio (2015) acota que para regular esta materia en el marco normativo peruano conviven normas administrativas y penales, las primeras han creado competencias específicas a órganos administrativos, sin embargo, esta convivencia ha generado diversos problemas de aplicación práctica, en especial en el referido momento de la intervención y competencias de las autoridades aduaneras y del Ministerio Público, y postula que "ante las sospechas de la comisión del delito de lavado de activos la intervención del Ministerio Público, como director de la investigación, debe realizarse desde la noticia criminis" (p. 164).

Las normas que reprimen el transporte transfronterizo de dinero deben ir acompañadas de normas administrativas que regulen el sistema de control de transporte de efectivo en las fronteras de los países, que deben estar acompañadas de un sistema de declaración y acreditación de los activos de origen ilícito en la vía del procedimiento administrativo. En el nuestro ordenamiento con la actual modificatoria de la Sexta Disposición Complementaria Transitoria Final de la Ley $N^{\circ} 28306$ que establece la obligación de declarar el ingreso y o salida de dinero en efectivo del país se opta por un sistema de declaración como lo exige la Recomendación Especial IX de 2004 y Recomendación 32 del GAFI.

La tabla 1 presenta la información relacionada con lagunas o vacíos legales. Se observa que 17 intervenciones con dinero incautado tienen un vacío, esto es el $77.27 \%$ mientras que el $5 \%$ se encuentra amparado legalmente con un $22,73 \%$. De los 17 casos que figuran con vacío legal (SI) se tiene que al momento de ser intervenidas las personas y verificar una transgresión en la norma DL. 1249, el fiscal en uso de sus facultades dispone la medida de incautación del dinero, en consecuencia, la Aduana culmina con su 
participación, no pudiendo sancionar con la multa del $30 \%$ al no proceder a la elaboración de ningún acta de retención.

\begin{tabular}{|c|c|c|}
\hline Estado & Frecuencia & $\%$ \\
\hline Si & 17 & 77.27 \\
\hline No & 5 & 22.73 \\
\hline Total & 22 & 100,0 \\
\hline
\end{tabular}

Fuente: Ficha de registro documental

Del total de intervenciones advertidas al ingreso al país desde el año 2015 al año 2018, ha ido aumentando de un monto de 11 (once) a 46 (cuarenta y seis) intervenciones. Por otro lado, respecto al total de intervenciones en salida, en el año 2015 se realizaron (12) intervenciones de dinero no declarado, cifra que se mantuvo al 2017, sin embargo, vemos que en el 2018 esta cifra disminuyó considerablemente, pues sólo se presentó una intervención de dinero no declarado en salida.

Esta variación significativa, se dio a partir del 16 de agosto de 2017, fecha en la cual se da inicio al Control Integrado Perú - Chile, donde las declaraciones de dinero al ingreso al país son controladas y verificadas en territorio peruano (CAF Santa Rosa) al ingreso con posterioridad al trámite migratorio, mientras que las declaraciones de dinero a la salida del país son entregadas a la Autoridad Aduanera Peruana en el Complejo Fronterizo de Chacalluta - Chile, a razón que es en el país vecino donde las personas efectúan el trámite migratorio de salida del país. A partir del 16 de agosto de 2017 se da inicio al Control Integrado Perú - Chile (CAF Santa Rosa), debilitándose el control de salida del país. Se verifica que desde el año 2015 hasta el 2017 la cantidad intervenciones de dinero no declarado en salida fue uniforme, y es en el año 2018 donde muestra una caída, advirtiéndose ausencia de control del dinero que sale del país. Por otro lado, el monto de intervenciones por dinero no declarado en el ingreso muestra que va en crecimiento. (Figura 01)

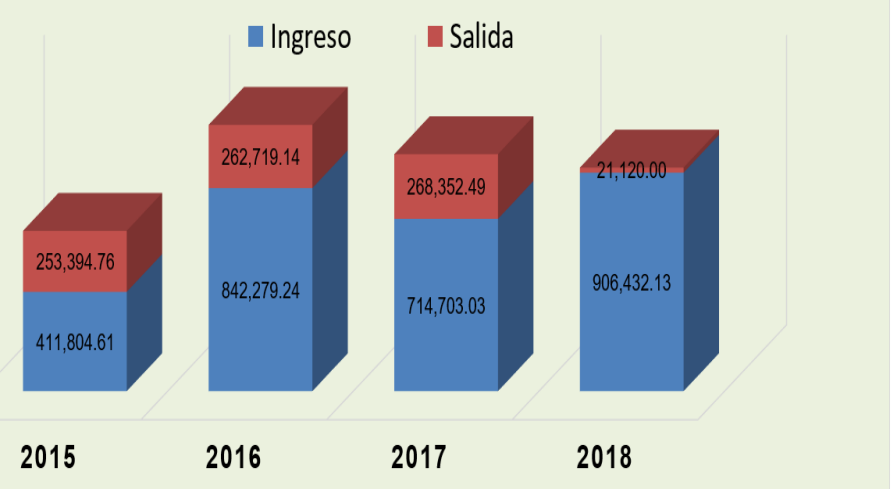

Figura 1

Resumen de monto intervenido (US\$) 
Se estima una constante disminución del monto intervenido en salida, iniciando en el año 2015 con $\$ 253,394.76$ y culminar en el 2018 con $\$ 21,120.00$, se deduce que ello se debe al inicio del Control Integrado en la cual se ha perdido el control de salida y a la falta de regulación respecto a las intervenciones por dinero no declarado en salida en territorio fronterizo. Se puede apreciar que el año con mayor monto de dinero en dólares, en las intervenciones de ingreso y salida se presentó en el 2016, (ingreso de \$ $842,279.24$ - salida de 262,719.14), con un total de $\$ 1,104,998.38$ dólares de los Estados Unidos de América. Y el año con menor monto de dinero intervenido fue en el año 2015 (ingreso $411,804.61$ y salida 253,394.76). El año 2018, fue el año con mayor monto de intervención de dinero encontrado al ingreso del CAF Santa Rosa, que se estima que una cantidad aproximada de intervenciones en salida podrían llevarse a cabo si el marco normativo logra adaptarse al acuerdo marco sobre control integrado Perú - Chile.

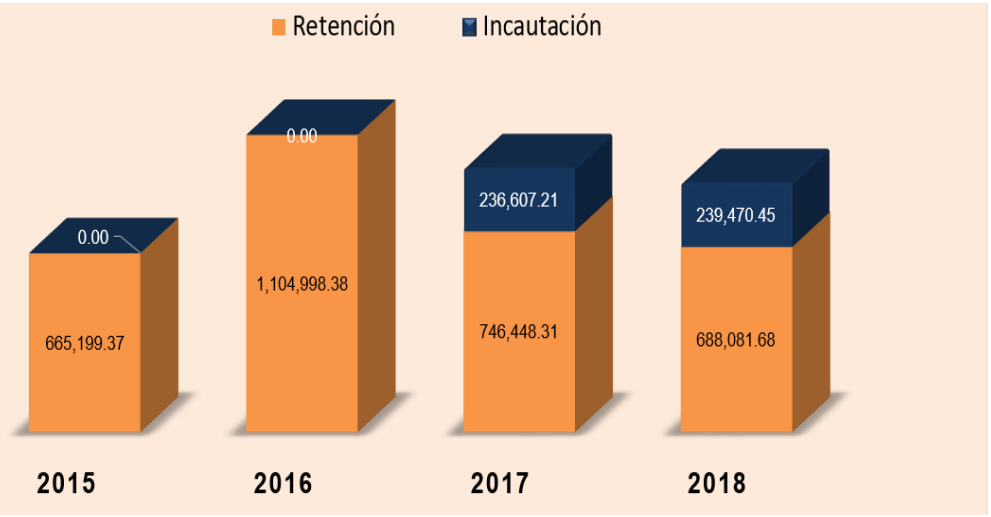

Figura 2

Retención / Incautación (Monto US\$̦)

En figura 2 se observa la información respecto del número de intervenciones de dinero retenido e incautado, así como los montos de dinero no declarado en el CAF Santa Rosa, durante los años 2015 al 2018. Es así que apreciamos que, respecto al tipo de intervención en los años 2015 y 2016, éstas solo fueron de retención dispuestas por la Autoridad Aduanera, mientras que los años 2017 y 2018 con la modificación normativa se da lugar a la figura de la Incautación dispuesta por el Ministerio Público. Respecto a las retenciones de dinero en el año 2015, se realizaron 23 retenciones, duplicándose en el año 2016 y manteniéndose con una cifra aproximada los años 2017 y 2018. En tanto las incautaciones de dinero del Ministerio Público suman un total de 22 intervenciones por los años 2017 y 2018. Durante el año 2018, se redujo las incautaciones, pero el monto de ellas aumentó, es decir que hubieron intervenidos trasladando mayores montos en frontera. A partir de la entrada en vigencia del Decreto Legislativo $N^{\circ} 1249$ (27.11.2016), que modifica la Sexta Disposición Complementaria y Transitoria y Final de la Le $\mathrm{N}^{\circ}$ 29306, el Ministerio Público en uso de sus atribuciones puede disponer la incautación de dinero no declarado. Esta modificatoria se ve reflejada en el presente cuadro, que muestra que durante los años 2015 no hubo incautaciones dispuestas por el MP, dado que ello no se encontraba aun regulado en la normativa. El fiscal, representante del Ministerio Público, dispone la incautación cuando considera que existen indicios razonables de que la persona intervenida se encuentre vinculada a un presunto delito de lavado de activos. siendo así, durante los años 2017 y 2018, el monto 
de dinero en dólares en las incautaciones fue de $\$ 236,607.21$ y $\$ 239,470.45$ respectivamente.

En función a la edad de las personas intervenidas el 27.3 \% corresponde a la escala de 20 a 30 años de edad, el $41 \%$ corresponde se encuentra entre los 31 y 40 años de edad, $13.5 \%$ corresponde a la escala de 41 a 50 años y el 18.2\% de la escala de 51 a 60 años. Respecto al sexo, el 77.28 son intervenidos de sexo masculino y el 22.72 son intervenidos de sexo femenino. Finalmente, de acuerdo a la nacionalidad el 68.2 son de nacionalidad peruana, el 27.3 de nacionalidad chilena y el 4.5 de nacionalidad venezolana. De la información anterior deducimos que las personas que ingresan y salen del Perú por el CAF Santa Rosa, intervenidas por omitir efectuar su declaración en su mayoría son de nacionalidad peruana, de sexo masculino, de las edades entre los 31 y 40 años. (figura 3)

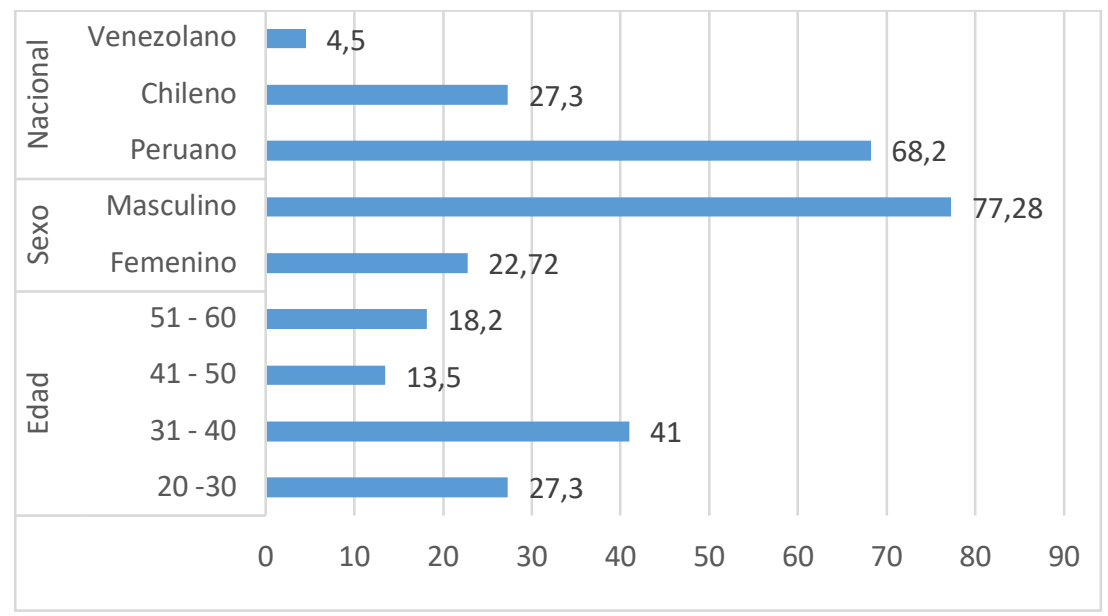

Figura 3

Características demográficas de los intervenidos, por traslado ilícito de dinero

Las multas generadas en el año 2016, ante las intervenciones de dinero retenido/incautado fue un acumulado de $S / 1,997,387.00$ configurando un $54.68 \%$, en el año 2017 la multa generada disminuyó a S/ 544,983.00 con un $14.92 \%$ y el 2018 se generaron multas por el valor de $S / 1,110,414.00$ con un $30.40 \%$ (Figura 4)

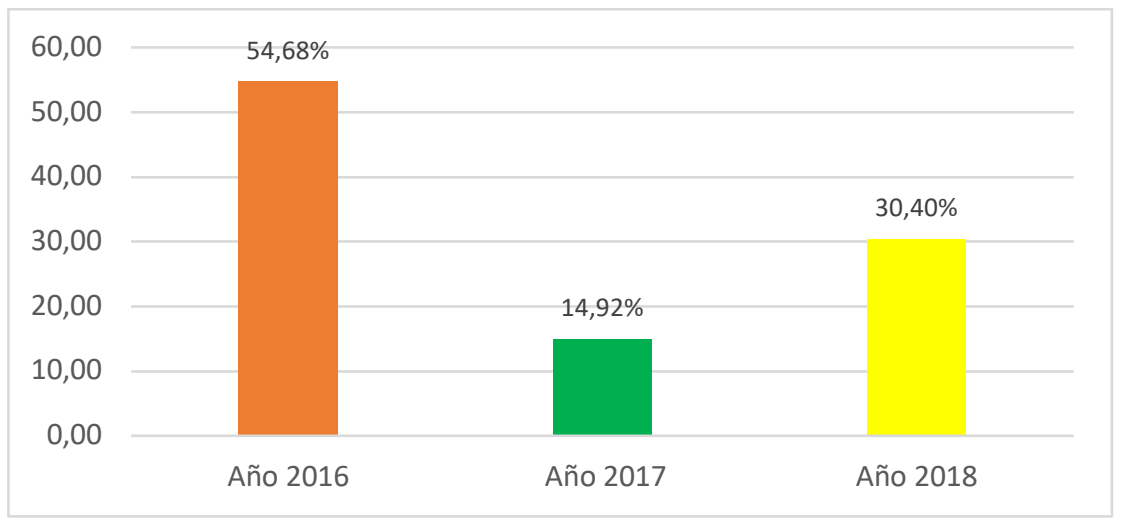

Figura 4

Multas generadas en intervenciones de dinero retenido e incautado 
Al presente año, aún existen montos pendientes de cancelación por multas generadas en el año 2016 y 2017, constituyendo un total S/ 746,559.00 soles en deuda por esos dos años. En cuanto a las multas generadas el 2018, se encuentran impago el monto de $\mathrm{S} / 932,722.00$. Por tanto, el total de monto impago por multas generadas por no haber declarado o haber declarado falsamente se tiene un total de $S / 1,679,281.00$.

Respecto a las modalidades de traslado, de dinero intervenido posteriormente incautado, se verifica que el 56,52\% trasladó el dinero adherido al cuerpo, un 34,78 \% no lo llevaba oculto, se entiende por no oculto al interior de la cartera, bolsillos, lugares donde con frecuencia se guarda mercancías, el 4,35 lo trasladaba oculto al interior del vehículo y un también un 4,35\% lo llevaba oculto envuelto al interior del equipaje.

\section{DISCUSIÓN}

La presente investigación tiene por objeto relacionar el marco normativo y la omisión a la sanción pecuniaria en la incautación de dinero por transporte transfronterizo en el Centro de Atención Fronteriza Santa Rosa. Las lagunas en la normatividad proveen de un espacio jurídico que en muchos casos son aprovechados para incorporar dinero ilegal al sistema financiero, Huayllani (2016), sostiene que el ocultamiento de dinero deviene de delitos que revisten gravedad, por lo que muchos países no solo enfrentan el problema con medidas punitivas, sino también preventivas. Los resultados del análisis del marco normativo indican que el decreto legislativo 1249 (modificatoria a la ley 283069, si contempla los casos en los cuales corresponde la retención de dinero o instrumento financiero negociable al portador y en consecuencia la aplicación de la sanción de multa del $30 \%$ del valor no declarado o declarado falsamente; pero no contempla los casos en los cuales corresponde la incautación de dinero, medida cautelar dispuesta por el fiscal, cuando existe indicios razonables de vinculación con el delito de lavado de activos, además la norma no contempla si procede la multa del $30 \%$ en los casos de incautación de dinero dispuesta por el Ministerio Público. (tabla $\mathrm{N}^{\circ} 01$ ) reporta que de un total de veintidós intervenciones de dinero incautado por Disposición Fiscal en los años 2017 y 2018, un monto de diecisiete casos han presentado inconvenientes en la aplicación de la norma debido a la deficiente técnica legislativa del DL 1249, que mezcla dos vías la administrativa y penal, negando participación alguna a la Autoridad Aduanera de poder accionar para aplicar la retención del dinero y demás consecuencias accesorias - determinación de infracciones y aplicación de sanciones, pues la autoridad Aduanera en función al principio de objetividad debe aplicar la norma de naturaleza administrativa mientras que el Ministerio Público como titular de la acción penal persigue el ilícito al presumir la comisión de un delito vinculado al Lavado de Activos. En suma la normatividad pone en evidencia los vacíos legales para luchar contra el traslado ilegal de dinero por las fronteras, de tal modo que según Guillén (2016), en los últimos 8 años el lavado de activos se ha incrementado en nuestro país a 12,840 millones de dólares, concluyendo que no existe unidad de criterio en los operadores de justicia para la aplicación de la validez de la prueba indiciaria en la investigación y judicialización del delito de lavado de activos proveniente del tráfico ilícito de dinero. 
Con respecto a las sanciones por omisión o falsa declaración del dinero, se observa que durante los años 2017 y 2018, se concretaron setenta y siete intervenciones de dinero donde se aplicó la medida la retención del dinero, en dichos casos la autoridad Aduanera retuvo el dinero, por disposición fiscal, quien no optó por incautar el dinero, en esa línea se evidencia la ausencia de un dispositivo legal que establezca la oportunidad de intervención del Ministerio Público y el momento en el que una intervención de tipo administrativa se transforma en una de tipo penal. Del mismo modo se reporta un vacío normativo con la incorporación de la Incautación de dinero, un total veintidós incautaciones. No existen criterios objetivos para la determinación entre una medida u otra (retención o incautación). En esa línea se observa que en ocho casos se intervino a ciudadanos portando el dinero sin evidencia de ocultamiento alguno, desconociendo los motivos por los cuales se dejó de lado la participación de la Autoridad Aduanera y se optó por el inicio de una investigación de índole penal. Que el marco normativo si contempla criterios objetivos para la determinar la retención, y no para la medida de incautación. Asimismo, se da cuenta de una deficiencia legislativa al no ajustarse a la realidad del Centro de Atención en Frontera - Santa Rosa que limita con el país de Chile, al observar que con la implementación del Control Integrado Perú - Chile ha disminuido las intervenciones de dinero en salida, iniciando con un monto de doce a culminar en el año 2018 con una intervención, ello se suma a la ausencia de un Protocolo de Intervención único que permita interactuar con más de una institución. Por otro lado, es claro el DL. 1249 al indicar que la autoridad aduanera como consecuencia accesoria a la retención del dinero por omisión o falsedad en la declaración de dinero en ingreso o salida del territorio nacional, aplica una sanción de multa equivalente al 30\% del dinero intervenido, sin embargo se advierte que la norma es deficiente y presenta un vacío legal significativo dado que no contempla el tratamiento a seguir en los casos de Incautación de dinero, tampoco precisa si corresponde la aplicación de la sanción de multa ni su oportunidad. Pues se ve de la tabla 07 que, de un total de noventa y nueve casos de intervenciones de dinero años 2017 y 2018, en setenta y siete casos se elaboró el Acta de Retención y se emitió la liquidación de cobranza aplicando la multa respectiva. Sin embargo, en los veintidós casos de incautación de dinero el tratamiento fue distinto y se encuentra reflejado en la tabla $\mathrm{N}^{\circ} 07$, al encontrarse en sede fiscal en medio de una intervención de tipo penal y no administrativa. Almonacid y Huamán (2014) en su investigación concluye que la mayor incidencia en el lavado de dinero se encuentra en las zonas de frontera, aduciendo que Tacna se encuentra en un nivel de riesgo alto, en el traslado ilegal de dinero, sin dejar de mencionar que esta actividad ilícita tienen como corolario muchos delitos precedentes.

De las veintidós intervenciones de dinero incautado, diecisiete intervenidos fueron sancionados con la aplicación de la sanción de multa del $30 \%$, que solo una persona cumplió con la sanción mientras que dieciséis con un porcentaje de $69.57 \%$ pese a haber sido notificadas se encuentran omitiendo dicha sanción con deuda al Estado. La reiterada omisión a la sanción pecuniaria en la incautación de dinero por transporte transfronterizo en el Centro de Atención Fronteriza Santa Rosa, está fuertemente influenciada u ocasionada por los vacíos legales que presenta el marco normativo que previene y reprime el Lavado de Activos en el Perú. El marco normativo que previene y reprime el Lavado de Activos en el Perú, presenta deficiencias técnicas y vacíos 
legislativos que contravienen los estándares internacionales y recomendaciones del GAFI, al evidenciar que la sanción pecuniaria dispuesta ante la comisión de la infracción al sistema de declaración de dinero transfronterizo es ineficaz y no disuasiva al comprobar el alto índice de incumplimiento. La Sexta Disposición Complementaria, Transitoria y Final de la Ley $\mathrm{N}^{\circ} 28306$, presenta múltiples modificatorias, que impiden establecer un criterio doctrinario uniforme en las intervenciones de dinero, entre los operadores Ministerio Público, SUNAT y PNP, al confundir la vía administrativa y penal. Entre el año 2017 y 2018 a pesar que la autoridad aduanera retuvo el dinero por transporte ilegal, al no haber declarado o haber declarado falsamente el dinero, el $26.09 \%$ se encuentran en calidad de no sancionados.

Es necesario la elaboración de un Protocolo Único de Intervención entre los operadores que ejercen funciones en el Centro de Atención en Frontera Santa Rosa - Tacna, entre el Ministerio Público, la SUNAT y la PNP para la aplicación de la normativa vinculada al dinero transfronterizo. Se recomienda delimitar en la Sexta Disposición Complementaria, Transitoria y Final de la Ley $\mathrm{N}^{\circ} 28306$ y modificatorias, la vía procedimental (administrativa y penal) a seguir en base a criterios objetivos, demarcando la oportunidad de actuación de las entidades involucradas y el dominio de la intervención en la lucha contra el lavado de activos, siguiendo las recomendaciones de GAFI acerca de transporte transfronterizo. Asimismo, también se recomienda la modificación normativa del Decreto Legislativo 1249, de manera tal que elimine el conflicto existente entre la medida de retención e incautación de dinero, ésta última debe desarrollarse en la normativa con mayor profundidad incorporando que se disponga en base a parámetros objetivos ya sea a través de equipos especializados como detectores de trazas y partículas de sustancias (TID) y modalidades de evasión al control aduanero (ocultamiento). Proponemos la modificación normativa del Decreto Legislativo 1249 que señale taxativamente la aplicación de la sanción de multa del dinero incautado, y su persecución para su cumplimiento efectivo ante la SUNAT, y la incorporación del descuento inmediato a cargo de la SUNAT, del monto incautado al momento de la notificación de la liquidación de Cobranza anexa a la Resolución de Intendencia que determina la infracción cometida y la multa aplicada.

\section{REFERENCIAS BIBLIOGRÁFICAS}

Almonacid, B. y Huaman, D. (2014). "El lavado de dinero: estimación y análisis por actividades y departamentos en el Perú. 2001- 2012. (Tesis de Grado) Universidad del centro del Peru".

Bajo Fernández, Miguel (2009). "El desatinado Blanqueo de Capitales". En política criminal y blanqueo de capitales. Bajo Fernández, Miguel y Bacigalupo, Silvana (Editores). Madrid: Marcial Pons.

Basaldua, Javier. (1992). "Derecho Aduanero". Buenos Aires: Editorial Abeledo Perrot.

Bobbio, Norberto. (1956). "Teoría General del Derecho". Turín: Editorial Debate.

Cosio Jara, Fernando. (2006). "Manual de Derecho Aduanero". Lima: Editorial Rodhas SAC.

Decreto Legislativo № 1053. Ley general de Aduanas. Publicado el 17 de junio de 2008. Diario Oficial El Peruano. Lima - Perú.

Decreto Legislativo $1106^{\circ}$ - Decreto Legislativo de lucha eficaz contra el lavado de activos y otros delitos relacionados a la minería ilegal y crimen organizado.

Veritas et Scientia Vol. 8 (2) Julio - diciembre 2019. 
Decreto Legislativo $1249^{\circ}$ - Decreto Legislativo que dicta medidas para fortalecer la prevención, detención y sanción del lavado de activos y el terrorismo.

Decreto Supremo 121-2003-EF, Reglamento de la Ley de los Delitos Aduaneros, del 27.08.2003.

Díaz Beltrán, T. (2016). "Análisis jurídico explicativo - propositivo del proceso de valoración de los indicios razonables realizado por el Poder Judicial y el Ministerio Público en el delito de Lavado de Activos, en procesos del distrito judicial de Arequipa, año 2013 - 2014".

Gallardo Miraval, J. (2008). "Los Delitos Aduaneros - Fundamentos del Comercio Internacional". Lima: Editorial Rodhas.

García de Enterría, E., T. Fernandez Rodriguez, T. "Curso de Derecho Administrativo". Tomo II. Lima: Palestra - Temis.

Gamarra Podbrscek, G. (2017). "Las sanciones aduaneras como medidas restrictivas del comercio: Una revisión a partir de la jurisprudencia del Tribula de Justicia de la Comunidad Andina" (Tesis de grado).

Guillén Enriquez, C. (2016). "Implementación de medidas en la lucha contra el lavado de activos proveniente del tráfico ilícito de drogas en la División de investigación de lavado de activos de la Dirección Antidrogas PNP durante el periodo 2012 al 2015". (Tesis de grado).

Gallardo Miraval, Juvenal. (2006). "Los Delitos Aduaneros, Fundamento de Comercio Internacional". Lima: Editorial Rodhas.

García Toma, Victor (2007). Introducción a las Ciencias Jurídicas. (2a. ed). Lima: Jurista Editores.

Huayllani Vargas, Huber (2016) "El Delito Previo en el Delito de Lavado de Activos 2016". (Tesis de grado).

Informe N 030-2014-SUNAT/2014 emitido por la Gerencia Jurídica Aduanera, de la Intendencia Nacional Jurídica, del 27.02.2014.

Kelsen, Hans (1987) Introducción a la Teoría Pura del Derecho, Buenos Aires: Editorial Eudeba.

Ley 28008. Ley de los Delitos Aduaneros, del 18.07.2003

Lentz, C. (2017). Alcances del Contenido de los artículos $39^{\circ}$ y $41^{\circ}$ de la Ley de los Delitos Aduaneros, Ley $N^{\circ} 28008$; y su adecuación al principio de Tipicidad" (Tesis de grado).

Martinez Bullé, Goyri, (1999) El Tránsito del Estado de Derecho al Estado Social de Derecho". Revista Peruana de Derecho Constitucional, Nro. 1. Lima: Tribunal Constitucional.

C. Northcote S. (2009). "Importancia del Principio de Tipicidad en el Procedimiento Administrativo Sancionador". Actualidad Jurídica, N 191, pp. VIII-1 - VIII-3.

Ore Sosa Eduardo (2018). "La Problemática del delito de lavado de Activos". El Delito de Lavado de Activos. Lima: Gaceta Jurídica S.A.

Prado Saldarriaga, Victor. (1994). El delito de Lavado de Dinero en el Perú: (Investigación).

Prado Saldarriaga, Victor. (1994). "El delito de Lavado de Dinero. Su tratamiento penal y bancario en el Perú". Lima: Editorial IDEMSA.

Prado Saldarriaga, Victor. (2013) "Criminalidad organizada y lavado de activos". Lima: IDEMSA

Ribó, Durán (1991), L. “Dic. De Derecho". Barcelona: Bosch casa Ed.

Rosas Castañeda, Juan A. (2015). "La Prueba en el Delito de Lavado de Activos". Lima: Gaceta Jurídica S.A.

Ros, Alf (2010). Sobre el Derecho y la Justicia. Buenos Aires: Eudeba.

Ruiz Sanchez, M. Valdiviezo Del Carpio, "Consideraciones en torno a la Responsabilidad de los Participantes, Postores y Contratistas en Contrataciones del Estado" Revista Derecho \& Sociedad, $\mathrm{N}^{\circ}$ 44, 2015.

Vaquero, R. (2004). Implementación de Políticas Públicas en México. México. 